\title{
Effect of Heat Treatment on Mechanical Properties and Microstructure of NST 37-2 Steel
}

\author{
D. A. Fadare*, T. G. Fadara and O. Y. Akanbi \\ Department of Mechanical Engineering, University of Ibadan, P.M.B 1, Ibadan, Nigeria \\ * Corresponding Author: fadareda@yahoo.com
}

\begin{abstract}
Engineering materials, mostly steel, are heat treated under controlled sequence of heating and cooling to alter their physical and mechanical properties to meet desired engineering applications. In this study, the effect of heat treatment (annealing, normalising, hardening, and tempering) on the microstructure and some selected mechanical properties of NST 37-2 steel were studied. Sample of steel was purchased from local market and the spectrometry analysis was carried out. The steel samples were heat treated in an electric furnace at different temperature levels and holding times; and then cooled in different media. The mechanical properties (tensile yield strength, ultimate tensile strength, Young's modulus, percentage reduction, percentage elongation, toughness and hardness) of the treated and untreated samples were determined using standard methods and the microstructure of the samples was examined using metallographic microscope equipped with camera. Results showed that the mechanical properties of NST 37-2 steel can be changed and improved by various heat treatments for a particular application. It was also found that the annealed samples with mainly ferrite structure gave the lowest tensile strength and hardness value and highest ductility and toughness value while hardened sample which comprise martensite gave the highest tensile strength and hardness value and lowest ductility and toughness value.
\end{abstract}

Keywords: Heat treatment; Mechanical properties; Microstructure; NST 37-2 steel

\section{INTRODUCTION}

Heat treatment is a combination of timed heating and cooling applied to a particular metal or alloy in the solid state in such ways as to produce certain microstructure and desired mechanical 
properties (hardness, toughness, yield strength, ultimate tensile strength, Young's modulus, percentage elongation and percentage reduction). Annealing, normalising, hardening and tempering are the most important heat treatments often used to modify the microstructure and mechanical properties of engineering materials particularly steels. Annealing is the type of heat treatment most frequently applied in order to soften iron or steel materials and refines its grains due to ferrite-pearlite microstructure; it is used where elongations and appreciable level of tensile strength are required in engineering materials $[1,2]$. In normalising, the material is heated to the austenitic temperature range and this is followed by air cooling. This treatment is usually carried out to obtain a mainly pearlite matrix, which results into strength and hardness higher than in asreceived condition. It is also used to remove undesirable free carbide present in the as-received sample [3]. Steels are normally hardened and tempered to improve their mechanical properties, particularly their strength and wear resistance. In hardening, the steel or its alloy is heated to a temperature high enough to promote the formation of austenite, held at that temperature until the desired amount of carbon has been dissolved and then quench in oil or water at a suitable rate. Also, in the harden condition, the steel should have $100 \%$ martensite to attain maximum yield strength, but it is very brittle too and thus, as quenched steels are used for very few engineering applications. By tempering, the properties of quenched steel could be modified to decrease hardness and increase ductility and impact strength gradually. The resulting microstructures are bainite or carbide precipitate in a matrix of ferrite depending on the tempering temperature.

Steel is an alloy of iron with definite percentage of carbon ranges from $0.15-1.5 \%$ [4], plain carbon steels are those containing $0.1-0.25 \%$ [5]. There are two main reasons for the popular use of steel: (1) It is abundant in the earth's crust in form of $\mathrm{Fe}_{2} \mathrm{O}_{3}$ and little energy is required to convert it to Fe. (2) It can be made to exhibit great variety of microstructures and thus a wide range of mechanical properties. Although the number of steel specifications runs into thousands, plain carbon steel accounts for more than $90 \%$ of the total steel output. The reason for its importance is that it is a tough, ductile and cheap material with reasonable casting, working and machining properties, which is also amenable to simple heat treatments to produce a wide range of properties [3]. They are found in applications such as train railroads, beams for building support structures, reinforcing rods in concrete, ship construction, tubes for boilers in power generating plants, oil and gas pipelines, car radiators, cutting tools etc [5].

NST 37-2 steel is one of the commercial plain carbon steel grades produced by the Delta Steel Company (DSC) in Aladja, Delta State, Nigeria [6]. It is widely used in Nigeria for manufacturing of machine parts and as structural member in building, road and bridge construction. Its heat treatability therefore will determine the extent of its application. To best of the authors' knowledge the heat treatability of this steel grade produced in Nigeria have not been evaluated. The objective of the present study is to investigate the effect of heat treatment (annealing, normalising, hardening, and tempering) on the mechanical properties and microstructure of NST 37-2 steel. 


\section{MATERIALS AND METHOD}

Sample of NST 37-2 steel bar with $25 \mathrm{~mm}$ diameter and $10 \mathrm{~m}$ long was purchased from a local market located in Ibadan, south-western, Nigeria. The chemical composition of the steel sample was determined as given in Tables 1 . Standard tensile and impact specimens were made from NST 37-2 steel sample using lathe machine. Samples were subjected to different heat treatment: annealing, normalising, hardening, and tempering in accordance to ASM International Standards [7]. The heat treatment conditions are listed in Table 2. Four specimens were prepared for each heat treatment type.

Table1: Chemical composition of NST 37-2 steel

\begin{tabular}{lllllllll}
\hline $\mathbf{C}(\%)$ & $\mathbf{S i}(\%)$ & $\mathbf{S}(\%)$ & $\mathbf{P ( \% )}$ & $\mathbf{M n}(\mathbf{\%})$ & $\mathbf{N i}(\%)$ & $\mathbf{C r}(\%)$ & $\mathbf{M o}(\%)$ & $\mathbf{V ( \% )}$ \\
\hline 0.3422 & 0.2020 & 0.0108 & 0.0049 & 0.7374 & 0.0067 & 0.0104 & 0.0011 & 0.0006 \\
\hline $\mathbf{W ( \% )}$ & $\mathbf{A s}(\%)$ & $\mathbf{S n}(\%)$ & $\mathbf{C o}(\%)$ & $\mathbf{A l}(\%)$ & $\mathbf{P b}(\%)$ & $\mathbf{Z n ( \% )}$ & $\mathbf{C u ( \% )}$ & $\mathbf{F e}(\%)$ \\
\hline 0.0065 & 0.0005 & 0.0022 & 0.0002 & 0.0013 & 0.0005 & 0.0013 & 0.0033 & 98.6824 \\
\hline
\end{tabular}

\subsection{Determination of Mechanical Properties}

Mechanical properties of the treated and untreated samples were determined using standard methods. For hardness testing, oxide layers formed during heat treatment were removed by stage-grinding and then polished. Average Brinell Hardness Number (BHN) readings were determined by taking two hardness readings at different positions on the samples, using a Brinell hardness tester. Impact energy was recorded using the Izod impact tester. For tensile properties, tensile specimens were loaded into a 2000-kg Mosanto Tensiometer hooked up to a data logger. Load-elongation data were recorded and converted into stress-strain graphs. Yield strength, ultimate (tensile) strength, Young's modulus and ductility (\% elongation and reduction) were determined based on these graphs, in accordance with ASTM standard test procedures (ASTM E18, ASTM E23, ASTM E8) [8-10].

Table 2: Heat treatment conditions

\begin{tabular}{ccccc}
\hline Condition & Annealed & Normalized & Hardened & Tempered \\
\hline Temperature, ${ }^{\circ} \mathrm{C}$ & 910 & 910 & 910 & 450 \\
Holding time, min & 90 & 90 & 40 & 90 \\
Cooling medium & Furnace & Air & Water & Air \\
\hline
\end{tabular}

\subsection{Microstructure Examination}

Microstructure examination of the treated and untreated samples was carried out. Each sample was carefully grounded progressively on emery paper in decreasing coarseness. The grinding surface of the samples were polished using $\mathrm{Al}_{2} \mathrm{O}_{3}$ carried on a micro clothe. The crystalline 
structure of the specimens were made visible by etching using solution containing $2 \%$ Nitric acids and 98\% methylated spirit on the polished surfaces. Microscopic examination of the etched surface of various specimens was undertaken using a metallurgical microscope with an inbuilt camera through which the resulting microstructure of the samples were all photographically recorded with magnification of 400 .

\section{RESULTS AND DISCUSSION}

\subsection{Effect of Heat Treatment on Mechanical Properties}

The effect of heat treatment (annealing, normalising, hardening, and tempering) on the mechanical properties (ultimate tensile strength, hardness, toughness, percentage elongation, and percentage reduction) of the treated and untreated samples is shown in Table 3. The tensile strength of the untreated specimen was $343.80 \mathrm{~N} / \mathrm{mm}^{2}$ and hardness value of $100.10 \mathrm{BHN}$, elongation $21.16 \%$, reduction 63.23\%, young modulus $465.78 \mathrm{~N} / \mathrm{mm}^{2}$, yield strength 217.31 $\mathrm{N} / \mathrm{mm}^{2}$ and toughness of $58.88 \mathrm{~J}$ were obtained.

Table 3: Mechanical Properties of heat treated and untreated NST 37-2 steel

\begin{tabular}{lccccccc}
\hline & \multicolumn{7}{c}{ Mechanical properties } \\
\cline { 2 - 8 } $\begin{array}{l}\text { Heat } \\
\text { treatment }\end{array}$ & $\begin{array}{c}\text { Tensile } \\
\text { strength } \\
\left(\mathrm{N} / \mathrm{mm}^{2}\right)\end{array}$ & $\begin{array}{c}\text { Hardness } \\
(\mathrm{BHN})\end{array}$ & $\begin{array}{c}\text { Toughness } \\
(\mathrm{J})\end{array}$ & $\begin{array}{c}\text { Percentag } \\
\mathrm{e}\end{array}$ & $\begin{array}{c}\text { Percentag } \\
\mathrm{e}\end{array}$ & $\begin{array}{c}\text { Yield } \\
\text { strength } \\
\left(\mathrm{N} / \mathrm{mm}^{2}\right)\end{array}$ & $\begin{array}{c}\text { Young } \\
\text { modulus } \\
\left(\mathrm{N} / \mathrm{mm}^{2}\right)\end{array}$ \\
\hline Untreated & 343.80 & 100.10 & 58.88 & 21.16 & 63.23 & 217.31 & 465.78 \\
Annealed & 325.42 & 95.95 & 64.10 & 23.24 & 71.94 & 209.47 & 562.00 \\
Normalised & 422.30 & 188.00 & 57.26 & 20.38 & 71.81 & 232.75 & 534.85 \\
Hardened & 678.70 & 460.50 & 24.67 & 8.42 & 41.14 & 288.05 & 1235.31 \\
Tempered & 385.42 & 131.00 & 60.70 & 21.00 & 76.92 & 228.52 & 535.17 \\
\hline
\end{tabular}

Comparing the mechanical properties of annealed sample with the untreated sample, annealed sample showed lower tensile strength (325.42 N/mm²), yield strength $209.47 \mathrm{~N} / \mathrm{mm}^{2}$ and hardness (95.95 BHN) and increase in reduction in area (23.24\%), elongation (71.94\%) and toughness $(64.10 \mathrm{~J})$. The decrease in tensile strength and hardness can be associated with the formation of soft ferrite matrix in the microstructure of the annealed sample by cooling.

The mechanical properties of the normalized specimen were found to be $422.30 \mathrm{~N} / \mathrm{mm}^{2}, 232.75$ $\mathrm{N} / \mathrm{mm}^{2}, 188 \mathrm{BHN}, 57.26 \mathrm{~J}, 71.81 \%$ and $20.38 \%$ for tensile strength, yield strength hardness, toughness, percentage reduction and percentage elongation, respectively. The increase in tensile strength and hardness as compared to annealed and untreated sample was due to proper 
austenising temperature at $910^{\circ} \mathrm{C}$ and higher cooling rate, which resulted in decrease in elongation and toughness, which was lower than those obtained for untreated and annealed samples due to pearlitic matrix structure obtained during normalization of NST 37-2 steel.

The mechanical properties of the hardened sample revealed that it had the highest value of tensile strength $678.70 \mathrm{~N} / \mathrm{mm}^{2}$, yield strength $288.05 \mathrm{~N} / \mathrm{mm}^{2}$ and highest hardness (460.5 BHN) were obtained. The specimen was austenised at $910^{\circ} \mathrm{C}$ for 40 minutes and then water quenched. This treatment increased the tensile strength and hardness but there was massive reduction in elongation, toughness and reduction in area 8.42\%, $24.67 \mathrm{~J}$ and $41.14 \%$, respectively.

The mechanical properties of tempered sample showed that the tensile strength, yield strength, toughness, hardness, percentage reduction and percentage elongation were $385.42 \mathrm{~N} / \mathrm{mm} 2$, $228.52 \mathrm{~N} / \mathrm{mm}^{2}, 60.70 \mathrm{~J}, 131 \mathrm{BHN}, 76.92 \%$ and 21.00\%, respectively. Comparing the mechanical properties of tempered sample with hardened sample, it was found that there was decrease in tensile strength and hardness at tempering temperature $450^{\circ} \mathrm{C}$ while the percentage elongation, toughness and percentage reduction increased which can be associated to the graphitisation of the precipitated carbides that resulted in the formation of ferrite at tempering temperature of $450^{\circ} \mathrm{C}$. This showed that tempering temperature improved the degree of tempering of the martensite, softening the matrix and decreased its resistance of plastic deformation. However, the test results showed that annealing treatment gave an elongation superior to any other heat treatment studied. The variability in ultimate tensile strength, percentage elongation, percentage reduction hardness and toughness of treated and untreated NST 37-2 steel are shown in Figures 1 to 5 , respectively.

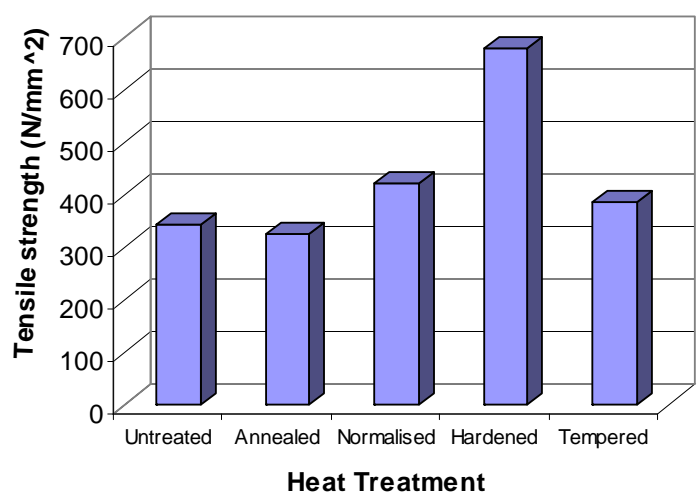

Fig. 1: Tensile Strength of treated and untreated samples of NST 37-2 steel 


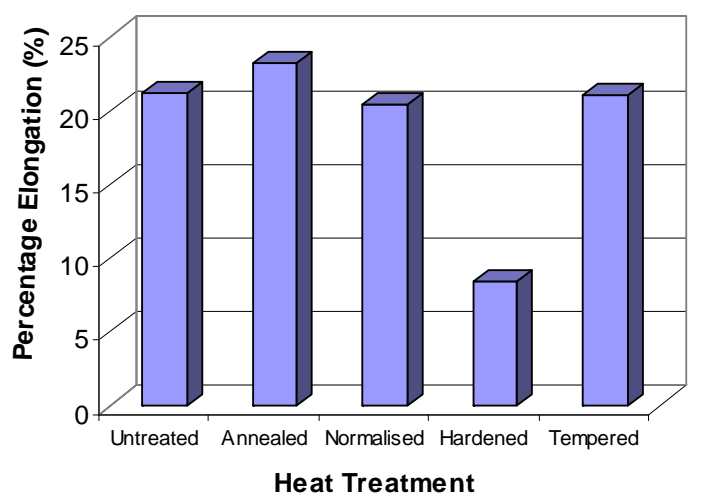

Fig. 2: Percentage elongation of treated and untreated samples of NST 37-2 steel

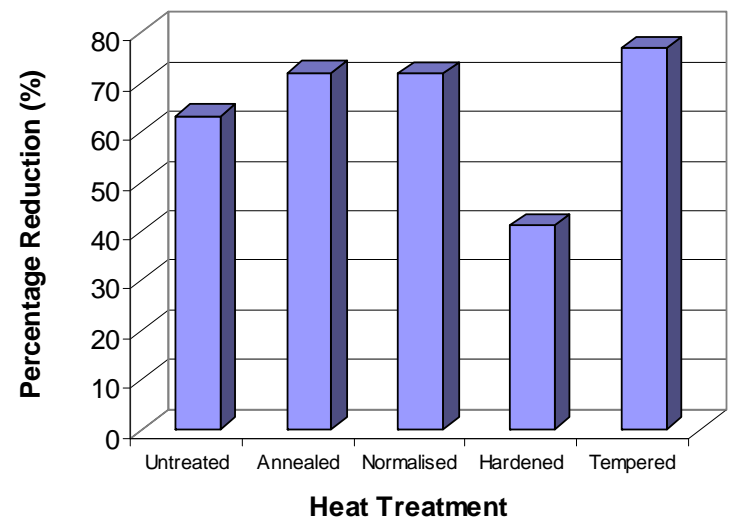

Fig. 3: Percentage reduction of treated and untreated samples of NST 37-2 steel

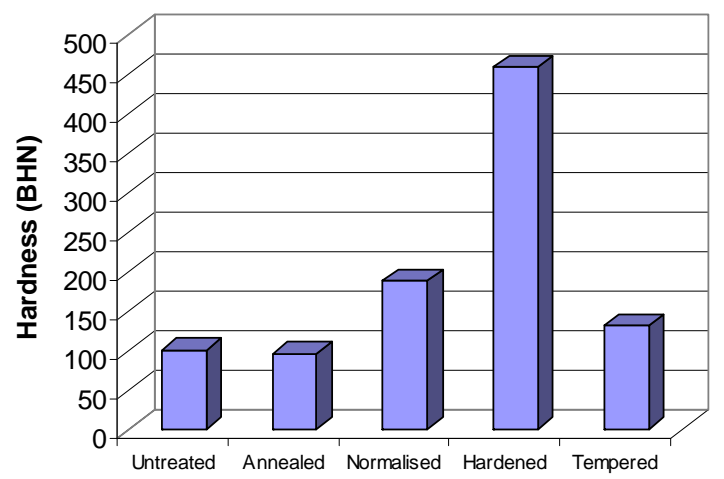

Heat Treatment

Fig. 4: Hardness of treated and untreated samples of NST 37-2 steel 


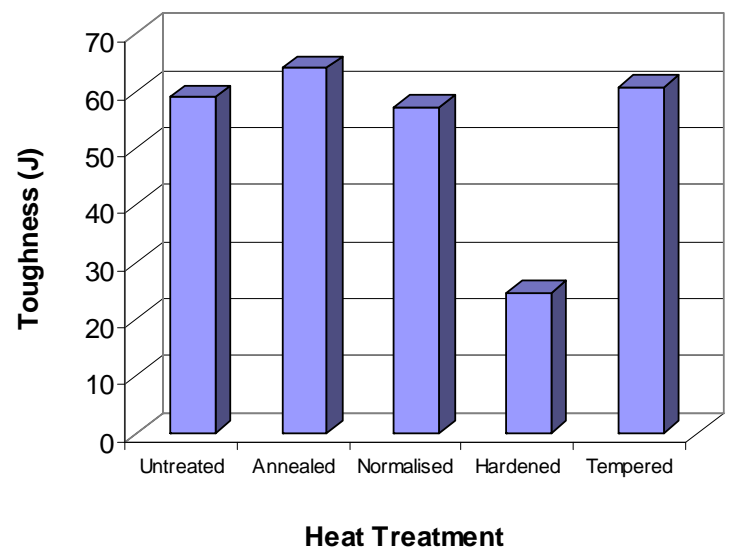

Fig. 5: Toughnes of treated and untreated samples of NST 37-2 steel

\subsection{Effect of Heat Treatment on Microstructure}

The microstructure of untreated specimen (Figure 6) showed a combination of ferrite (white) and pearlite (black), while the microstructure of the annealed sample is shown in Figure 7. As it can be seen in Figure 7, the ferrite grains had undergone complete recrystallization and these constituted the major portion of the microstructure the annealed medium carbon steel with stress free matrix. At $910^{\circ} \mathrm{C}$ the deformed structure was fully homogenised and during the slow cooling from austenizing range to room temperature the final microstructure consisted of fine ferrite grains in which the pearlite was more uniformly distributed. Figure 8 shows the microstructure of the normalized NST 37-2 steel. The normalized sample showed that the shape and size of the original austenite grains were influenced to a remarkable extent. The sample revealed a pearlitic matrix in which shorter graphite flakes than in annealed sample existed. It was observed that there was many short graphite flakes surrounded with patches of uniformly distributed pearlite grains as seen in Figure 8.

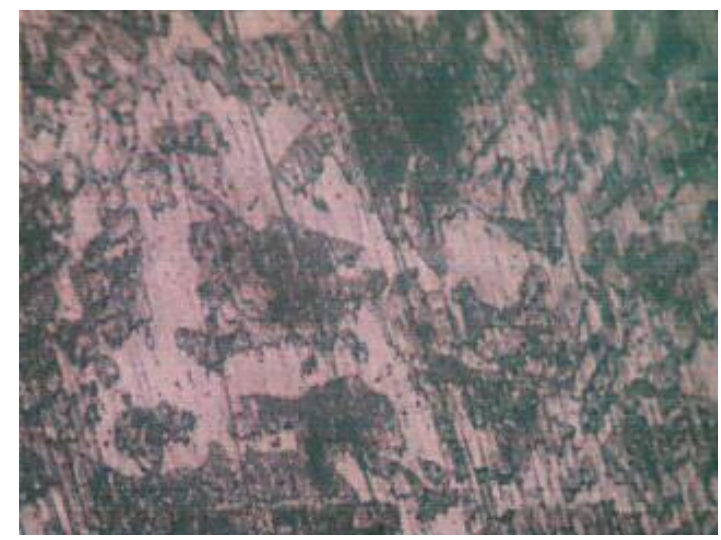

Fig. 6: Microstructure of untreated NST 37-2 steel (x400) 


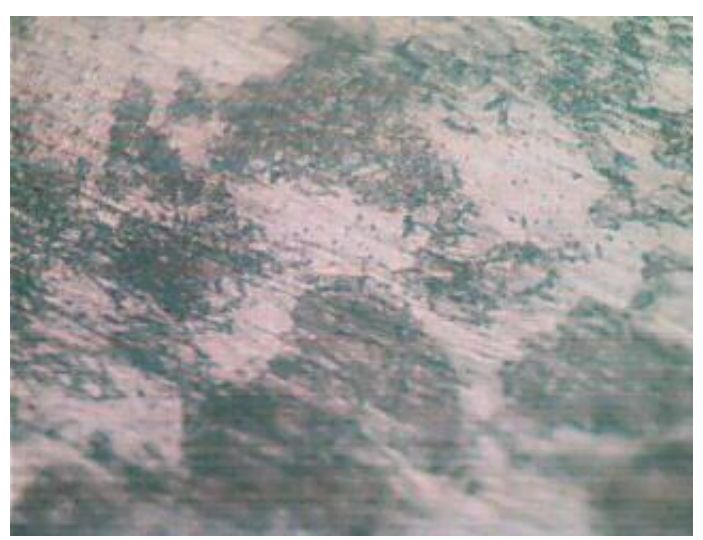

Fig 7: Microstructure of annealed NST 37-2 steel (x400)

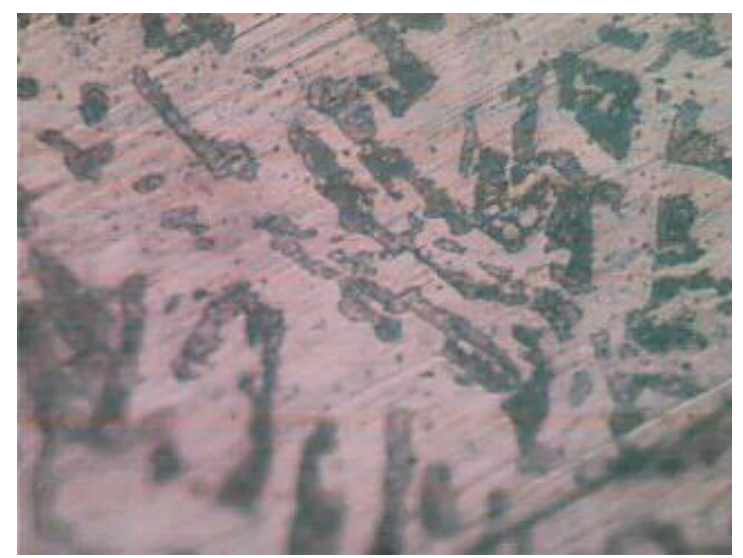

Fig. 8: Microstructure of normalised NST 37-2 steel (x400)

Figure 9 shows the massive martensite structure of hardened sample, when medium carbon steels are rapidly quenched from its austenite temperature to room temperature, the austenite will decompose into a mixture of some medium carbon martensite and fewer pearlite as a result of this microstructure which is hard, hence, there was increase in tensile strength, hardeness and reduction in ductility of the material [11].

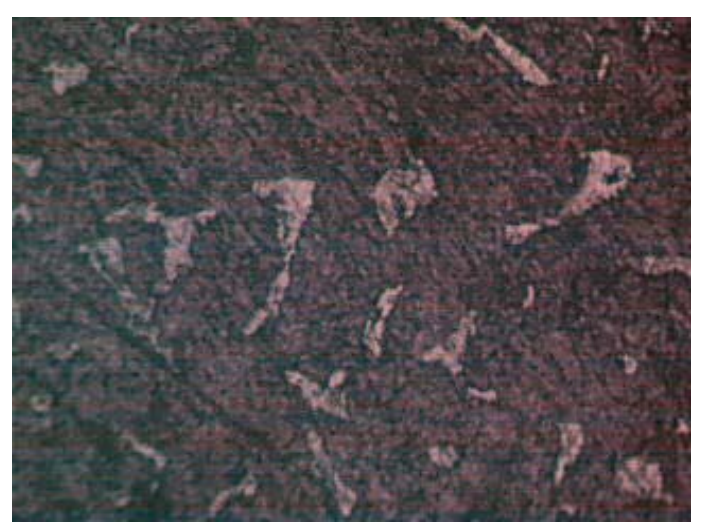

Fig. 9: Microstructure of hardened NST 37-2 steel (x400) 
The microstructure of hardened and tempered at $450^{\circ} \mathrm{C}$ is show in Figure 10. A highly recrystalised ferrite grains (white dotted areas) with some secondary graphite site was observed. This micrograph revealed that the microstructure of tempered specimen consisted of a number of appreciable carbide particles precipitated out from the matrix, which indicated that the precipitate carbide particles decomposed by a process of solution in ferrite matrix [12, 13]. The summary of the observed microstructure of treated and untreated NST 37-2 steel is given in Table 4.

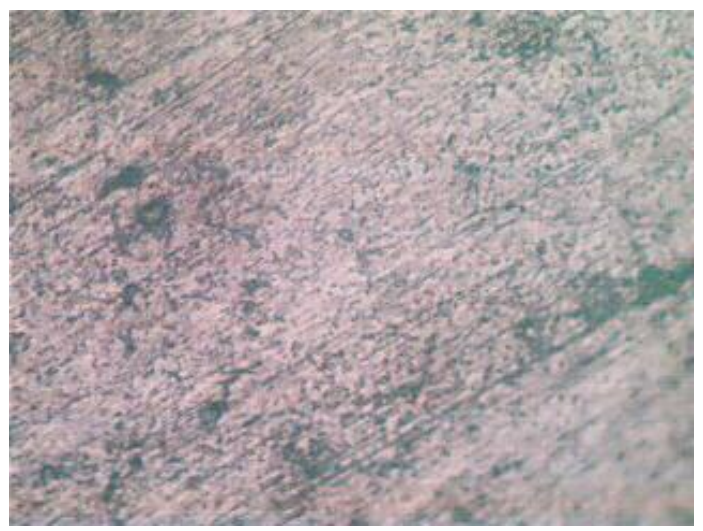

Fig. 10: Microstructure of tempered NST 37-2 steel (x400)

Table 4: Summary of microstructure of treated and untreated NST 37-2 steel

\begin{tabular}{cc}
\hline Heat treatments & Microstructure Developed \\
\hline Untreated & Graphite flakes in ferrite and pearlite matrix \\
Annealed & Graphite flakes in ferrite matrix \\
Normalising & Graphite flakes in pearlite matrix \\
Hardened & Graphite flakes in martensite matrix \\
Tempered & Graphite flakes in martensite matrix with recrystalised ferrite grains \\
\hline
\end{tabular}

\section{CONCLUSIONS}

From the results of investigation on the effect of heat treatment on mechanical properties and microstructure of NST 37-2 steel, the following conclusions were made:

Tensile strength, yield strength and hardness of medium carbon NST 37-2 steel increased with plastic deformation while ductility and impact strength decreased due to strain hardening effect.

Normalization treatment had also resulted in higher tensile strength and hardness than annealed samples. This treatment is recommended as final treatment after manufacturing. 
The tempered samples gave an increase in tensile strength and hardness than untreated sample as a result of formation of tempered martensite and resultant ferrite structure that were obtained. Hardened sample had the highest tensile strength and hardness with lowest ductility and impact strength when compared to other heat treated samples. Hardening is strongly recommended when the strength and hardness are the prime desired properties in design.

The mechanical properties of NST 37-2 steel can be altered through various heat treatments. The results obtained confirmed that improvement in mechanical properties that can be obtained by subjecting NST 37-2 steel to different heat treatments investigated in this study.

\section{REFERENCES}

[1] Kempester M.H.A., 1984, Materials for Engineers, $3^{\text {rd }}$ Edition. Hoodder and Stonghton.

[2] Raymond A., Higgins B., 1985, Properties of Engineering Materials. Hoodder and Stonghton.

[3] Dell, K.A., 1989, Metallurgy Theory and Practical Textbook. American Technical Society, Chicago, pp. 351-353.

[4] John, V.B., 1980, Introduction to Engineering Materials, $2^{\text {nd }}$ Edition. Macmillan Publishing Company Ltd., pp 321-324.

[5] Alawode, A.J., 2002, Effects of Cold Work and Stress Relief Annealing Cycle on the Mechanical Properties and Residual Stresses of Cold-Drawn Mild Steel Rod. M. Eng Thesis, Mechanical Engineering Department, University of Ilorin, Nigeria.

[6] Nigerian Society of Engineers (NSE). 2001, Professional Development Board Codes and Ethics Committee. Report On Workshop On Evaluation of Engineering Standards in Nigeria.

[7] ASM International 1991, ASM Handbook: Heat Treatment, Vol. 4, American Society for Metals Park, Ohio.

[8] ASTM E18. 2008, Standard Test Method for Rockwell Hardness of Metallic Materials, American Society of Testing and Materials.

[9] ASTM E23. 2008, Standard Test Method for Izod Bar Impact Testing of Metallic Materials, American Society of Testing and Materials.

[10] ASTM E8. 2008, Standard Test Method for Tension Testing of Metallic Materials, American Society of Testing and Materials.

[11] Jokhio, M.H., 1991, Effect of Retained Austenite on Abrasive Wear Resistance of Carburised SAE 8822H Steel. Thesis in Manufacturing Engineering, Mehran University of Engineering and Technology, Jamshoro.

[12] Charkrabarti, A.K. and Das, P.P. 1974. "Kinectics of Second stage graphitization in Quenched Alloy Spheroidal Iron.” Journal of British Foundryman, Vol. 67, pp. 330-334.

[13] Charkrabarti, A.K. and Das, P.P. 1988, “Tempering Characteristic of Quenched Alloy Spheroid Graphite Cast Iron.” Journal of British Foundryman, Vol. 67, pp. 330-334. 